\title{
Kinetics of Hydride Transfer from Metal-Free Hydride Donors to $\mathrm{CO}_{2}$
}

\author{
Ravindra B Weerasooriya,1,2 Jonathan L Gesiorski,1,2 Abdulaziz Alherz, ${ }^{3}$ Stefan Ilic,5 George N Har- \\ genrader,1,2 Charles B Musgrave, ${ }^{3,4}$ and Ksenija D Glusac* 1,2 \\ ${ }^{1}$ Department of Chemistry, University of Illinois at Chicago, 845 W Taylor Street, Chicago, Illinois 60607, United States \\ ${ }^{2}$ Chemical Sciences and Engineering Division, Argonne National Laboratory, 9700 Cass Ave, Lemont, Illinois, 60439, \\ United States \\ ${ }^{3}$ Department of Chemical and Biological Engineering, University of Colorado, Boulder, Colorado 80309, United States \\ ${ }^{4}$ Department of Chemistry, University of Colorado, Boulder, Colorado 80309, United States \\ ${ }^{5}$ Department of Chemistry, Virginia Polytechnic Institute and State University, Virginia, 24061, United States
}

KEYWORDS: $\mathrm{CO}_{2}$ reduction, organo-hydrides, Marcus theory, product selectivity, hydride transfer, formate

\begin{abstract}
Selective reduction of $\mathrm{CO}_{2}$ to formate represents an ongoing challenge in photoelectrocatalysis. To provide mechanistic insights, we investigate the kinetics of hydride transfer $(\mathrm{HT})$ from a series of metal-free hydride donors to $\mathrm{CO}_{2}$. The observed dependence of experimental and calculated HT barriers on the thermodynamic driving force was modeled using the Marcus hydride transfer formalism to obtain the insights into the effect of reorganization energies on the reaction kinetics. Our results indicate that, even if the most ideal hydride donor were discovered, the $\mathrm{HT}_{\text {to }} \mathrm{CO}_{2}$ would exhibit sluggish kinetics (less than 100 turnovers at $0.1 \mathrm{eV}$ driving force), indicating that the conventional HT may not be an appropriate mechanism for Solar conversion of $\mathrm{CO}_{2}$ to formate. We propose that the conventional HT mechanism should not be considered for $\mathrm{CO}_{2}$ reduction catalysis and argue that the orthogonal HT mechanism, previously proposed to address thermodynamic limitations of this reaction, may also lead to lower kinetic barriers for $\mathrm{CO}_{2}$ reduction to formate.
\end{abstract}

The conversion of $\mathrm{CO}_{2}$ to value-added products is a promising approach to mitigate the effect of increasing levels of $\mathrm{CO}_{2}$ in the atmosphere. The two-electron proton-coupled reduction of $\mathrm{CO}_{2}$ to formic acid represents an attractive transformation because the product can serve as a fuel with high volumetric energy density, easy handling, and low toxicity, or as a reagent in pharmaceutical industry and other synthesis applications. ${ }^{1,2}$ However, the selective reduction of $\mathrm{CO}_{2}$ to formate remains a challenge, and most transition metals catalyze the competing reactions, such as formation of $\mathrm{CO}$ and/or $\mathrm{H}_{2}{ }^{3-8}$ Only a handful of well-defined molecular catalysts, have been shown to lead to the selective formate formation. ${ }^{9-17}$ The product selectivity is generally controlled by either the thermodynamics or kinetics of the reaction between reduced metal and available substrates, namely protons and $\mathrm{CO}_{2 .}{ }^{14,18-21}$

In natural photosynthesis, $\mathrm{CO}_{2}$ is first captured from air and converted to 1,3-bisphosphoglycerate, which is then reduced via the hydride transfer (HT) from the NADPH cofactor. ${ }^{22}$ Following in nature's footsteps, our group recently developed hydrides that mimic NADPH activity, and that are sufficiently hydridic to perform a direct reduction of $\mathrm{CO}_{2}{ }^{23-}$ 28 Our work has shown how the thermodynamic hydricities of metal-free hydrides can be tuned using aromatization, delocalization and hyperconjugation mechanisms and that the benzoimidazole-based hydride $\mathrm{C} 4 \mathrm{H}$ (Figure 1) can efficiently reduce $\mathrm{CO}_{2}$ to formate via the HT mechanism. ${ }^{26} \mathrm{We}$ also demonstrated that the benzoimidazole-based hydrides can be efficiently regenerated electrochemically by optimizing the conditions for proton-coupled electron transfer, reporting the first proof-of-principle demonstration toward metal-free and selective $\mathrm{CO}_{2}$ reduction catalysis. ${ }^{24,27}$ Despite the successful demonstration of $\mathrm{HT}$ to $\mathrm{CO}_{2}$, the kinetics of the transformation were quite slow in our studies, on the timescale of several hours.

Herein, we report the results of our investigation of the factors that controlling the kinetics of HT from metal-free hydrides to $\mathrm{CO}_{2}$ by determining, both experimentally and computationally, the HT barriers of the series of hydride donors shown in Figure 1. As expected, our studies reveal that HT kinetics are improved by increasing the thermodynamic driving force of the reaction. The experimental data were 


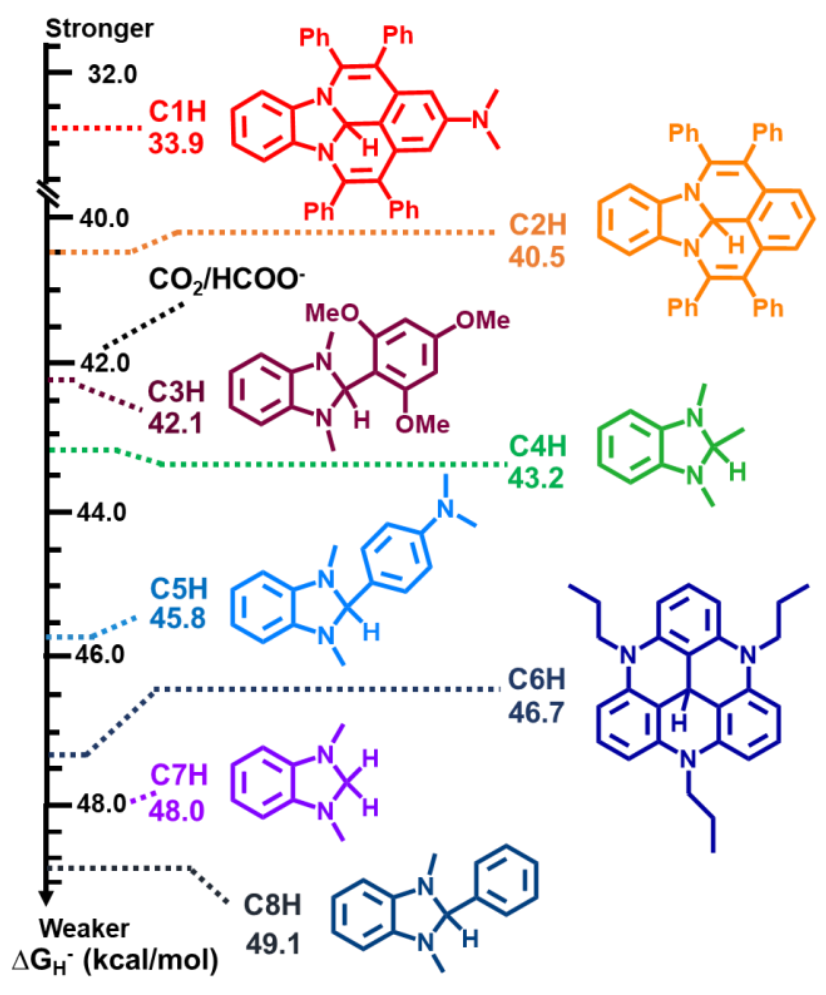

Figure 1. Structures and thermodynamic hydricities of hydride donors in DMSO. The hydricities were calculated at the wB97x-D 6-311+G(d,p) level of theory (computational details are provided in SI, Section S2). The hydridicity of formate was obtained from literature. ${ }^{29}$

fit to the Marcus hydride transfer model to obtain the relevant self-exchange reorganization energies of the metal-free hydrides and $\mathrm{CO}_{2} / \mathrm{HCO}_{2}{ }^{-}$couple. Our results show that the self-exchange reorganization energies of metal-free hydrides are relatively large $(91 \mathrm{kcal} / \mathrm{mol})$, indicating that the appropriate modification of the hydride donor structure yield lower reorganization energies and improved kinetics for HT. However, we find that, even if optimal hydride donors were used, the $\mathrm{HT}$ to $\mathrm{CO}_{2}$ would still be relatively slow, due to the large self-exchange reorganization energy associated with the $\mathrm{CO}_{2} / \mathrm{HCO}_{2}$ - couple $(41 \mathrm{kcal} / \mathrm{mol})$. Our results provide an explanation for why the formate ion is a rarely observed product in electrocatalytic $\mathrm{CO}_{2}$ reduction and point to possible approaches that can be used to circumvent the limitations of direct HT mechanism.

The synthesis and characterization of model compounds $\mathrm{C} 1 \mathrm{H}$ to $\mathrm{C} 8 \mathrm{H}$ is described in SI, Section $\mathrm{S} 1$. The driving force for HT from organic hydrides to $\mathrm{CO}_{2}$ was evaluated as the difference between the thermodynamic hydricities $\left(\Delta \mathrm{G}^{-}\right)$of organic hydrides and of formate $\left(\left(\Delta \mathrm{GH}^{-}=42 \mathrm{kcal} / \mathrm{mol}^{29}\right)\right.$ in DMSO. The $\Delta \mathrm{G}_{\mathrm{H}^{-}}$values for organic hydrides were calculated using the DFT methodology that was previously shown to agree with experimental values ${ }^{24}$ (See SI, Section S2, for computational details). Our results indicate that the strength of hydride donors can be improved in structures where the benzoimidazole and aryl moieties are co-planar $(\mathrm{C} 1 \mathrm{H}$ and $\mathrm{C} 2 \mathrm{H})$ or by introducing electron-donating amino and methoxy groups $(\mathrm{C} 1 \mathrm{H}, \mathrm{C} 3 \mathrm{H}, \mathrm{C} 5 \mathrm{H})$. Overall, the driving force for $\mathrm{HT}$ from these hydrides to $\mathrm{CO}_{2}$ varies between -11 to $+5 \mathrm{kcal} / \mathrm{mol}$ range (Table S2, SI). The HT driving forces are close to $\Delta \mathrm{G}=0$, which is the optimal range for applications in electrocatalysis (if $\Delta \mathrm{G}$ values were more negative, HT kinetics would likely improve, but the electrochemical regeneration of the hydride would require larger overpotentials). ${ }^{27,28}$

Experimental reaction conditions were tested for $\mathrm{CO}_{2}$ reduction by organo-hydrides to maximize the formate yield with respect to temperature, pressure, and solvent (SI, Section S1C). Optimal formate production was achieved at high temperatures $\left(100^{\circ} \mathrm{C}\right)$, mild $\mathrm{CO}_{2}$ pressure $(\sim 2.2 \mathrm{~atm})$ and in a polar medium (obtained by adding potassium salts to DMSO). An increase in the temperature lead to an increase in formate yields (Figure S1) consistent with the large kinetic barrier associated with HT. The increased polarity of the medium, either by solvents with higher dielectric con$\operatorname{stant}^{30,31}$ (SI, Figures S2 and S3) or by adding alkali and alkaline salts (Figure S4) leads to an increased in formate yields, as expected for a reaction that produced charged products from neutral reactants. $26,32,33$ In all reactions, the loss of organic hydride reactants was higher than the growth of formate product (blue and red traces in Figures S1-S5), indicating additional reaction pathways that organic hydrides undergo. While the detailed investigation of this side reaction was not performed, we hypothesize that it involves the reduction of DMSO to DMS, based on the observed NMR peak at $2.01 \mathrm{ppm}$ (Figure S6). Additionally, the calculated reaction free energy between DMSO and organohydrides were found to be extremely favorable (See Section S2.B, SI), further confirming that the side reaction may involve DMSO reduction.

We next analyzed the kinetics of HT reactions using organohydrides at the optimized conditions using ${ }^{1} \mathrm{H}$-NMR spectroscopy. Figure 2 illustrated the kinetic analysis for $\mathrm{C} 4 \mathrm{H}$, while the results for other hydrides are shown in Table S2 and Figures S7-S14, SI. Peaks associated with the hydride donor $\mathrm{C} 4 \mathrm{H}$ (at 6.52 and $6.35 \mathrm{ppm}$ ) were found to decrease in intensity, while a concomitant increase in the 

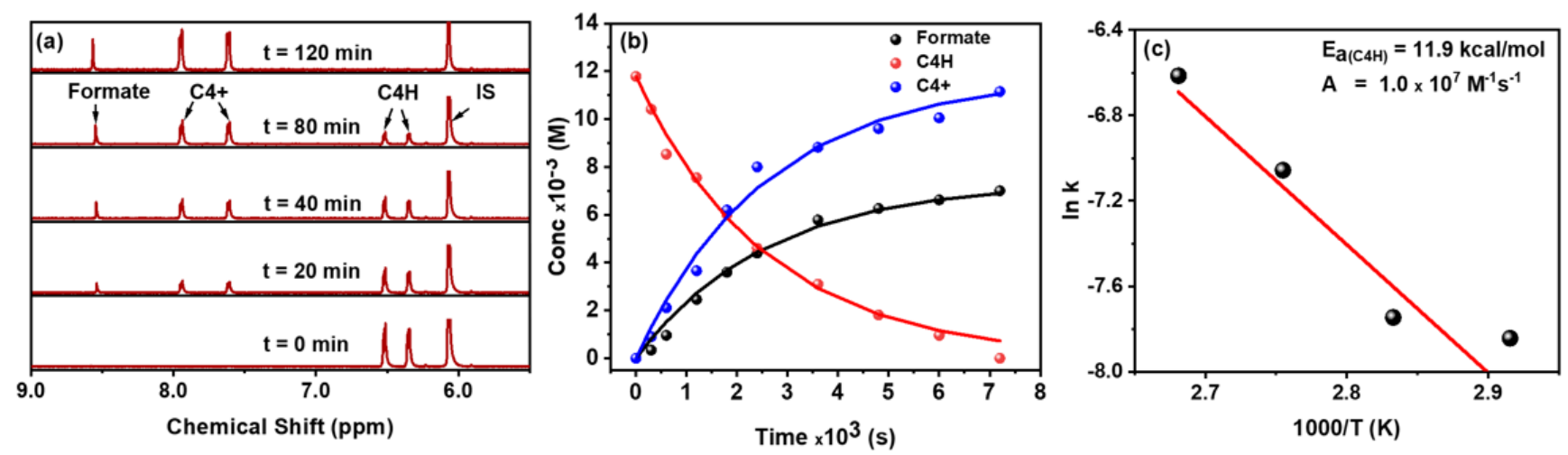

Figure 2. (a) ${ }^{1} \mathrm{H}-\mathrm{NMR}$ spectra of a reaction mixture containing $\mathrm{C} 4 \mathrm{H}$ and $\mathrm{CO}_{2}$ in DMSO-d6. Reaction conditions: $[\mathrm{C} 4 \mathrm{H}]=0.01$ $\mathrm{M},\left[\mathrm{KBF}_{4}\right]=0.20 \mathrm{M}, \mathrm{P}_{\mathrm{CO} 2}=\sim 2.2 \mathrm{~atm}, \mathrm{t}=100^{\circ} \mathrm{C}$, and reaction times of $0,20,40,80$ and 120 minutes. 1,3,5-Trimethoxybenzene $(0.05 \mathrm{M})$ was introduced as an internal NMR standard. (b) Scatter plot of reactant and product concentrations as a function of time for the reaction between $\mathrm{C} 4 \mathrm{H}(0.1 \mathrm{M})$ and $\mathrm{CO}_{2}(1.5 \mathrm{M})$. The solid lines represent the fits obtained using the kinetic model described in Section S1C, SI. (C) Plot of lnk vs $1 / \mathrm{T}$ for the reaction between $\mathrm{C} 4 \mathrm{H}$ and $\mathrm{CO}_{2}$.

formate ion (at $8.5 \mathrm{ppm}$ ) and the conjugate hydride acceptor $\mathrm{C}^{+}$(at 7.94 and $7.61 \mathrm{ppm}$ ) peaks were observed (Figure 2a). The increase in the $\mathrm{C}^{+}$concentration does not match the increase in the formate ion concentration (blue and black traces in Figure 2b), indicating that an additional HT pathway occurs (possibly reduction of DMSO, as discussed in the previous paragraph). Thus, the experimental HT data were fit to kinetic models that account for the side HT reactions (model details are available in the Section S1C, SI). The kinetic data fitting enabled the derivation of rate constants $\mathrm{k}_{\mathrm{HT}}$ for $\mathrm{HT}$ from hydride donors (R-H) to $\mathrm{CO}_{2}:$

$$
\mathrm{CO}_{2}+\mathrm{RH} \rightarrow \mathrm{R}^{+}+\mathrm{HCOO}^{-} \quad \mathrm{k} \mathrm{HT}
$$

The resulting rate constants values are in the $2 \cdot 10^{-6}$ to $2 \cdot 10^{-4} \mathrm{M}^{-1} \mathrm{~s}^{-1}$ range (Table S2, SI). Subsequent temperature-dependent kinetic experiments were performed to determine free energy barriers $\Delta \mathrm{G}^{\ddagger}$ and the Arrhenius preexponential factors for HT reactions. These experiments were performed for $\mathrm{C} 4 \mathrm{H}, \mathrm{C} 5 \mathrm{H}$ and $\mathrm{C} 7 \mathrm{H}$ (Figures $2 \mathrm{c}$ and S14a and $b$ ), while other hydrides could not be measured because of the narrow temperature window in which detectable $\mathrm{HT}$ to $\mathrm{CO}_{2}$ was observed. The free energy barriers for other hydride donors were thus evaluated by taking an average pre-exponential factor of $1 \cdot 10^{7} \mathrm{M}^{-1} \mathrm{~s}^{-1}$ (which was obtained from $\mathrm{C} 4 \mathrm{H}, \mathrm{C} 5 \mathrm{H}$ and $\mathrm{C} 7 \mathrm{H}$ temperature-depended kinetic experiments). Using this pre-exponential factor, the experimental free energy barriers were found to range from 15 to $21 \mathrm{kcal} / \mathrm{mol}$ (Table S2). The experimentally determined free energy barriers are in good agreement with DFT-computed values (Table S2 and Section S2), except for $\mathrm{C} 1 \mathrm{H}$ and $\mathrm{C} 2 \mathrm{H}$, where experiment yields much larger barriers than the computationally predicted values. We associate this mismatch to the poor solubility of these hydrides in DMSO, which results in aggregation and low reactivity observed in the experiment. The optimized transition state structures of R-H- $-\mathrm{CO}_{2}$ (Figure S19) demonstrate that $\mathrm{CO}_{2}$ aligns parallel to the benzimidazole $\mathrm{C}-\mathrm{N}$ bond, where the partial negative charge on $\mathrm{O}$ is stabilized by farranging interactions $(<3.5 \AA)$ with the $\mathrm{N}$ of the five- member ring. Faster kinetics can be correlated to several structural properties, such as shorter $\mathrm{R}-\mathrm{H}$ bond lengths, longer $\mathrm{H}-\mathrm{CO}_{2}$ bond lengths and more linear $\mathrm{HT}(\mathrm{C}-\mathrm{H}-\mathrm{C})$ angles (Table S8) and all factors indicating an early transition state.

The Marcus HT formalism ${ }^{34-36}$ was applied to the observed rate dependence on the thermodynamic driving force $\left(\Delta \mathrm{G}^{0}\right)$, with the goal of evaluating the self-exchange reorganization energies associated with $\mathrm{HT}$ to $\mathrm{CO}_{2}$. According to Marcus theory, the reaction barrier $\Delta \mathrm{G}^{\ddagger}$ can be expressed as:

$$
\Delta G^{\ddagger}=W_{r}+\frac{\lambda}{4}+\frac{\Delta G^{0}}{2}+\frac{\Delta G^{0^{2}}}{4 \lambda}
$$

Where $\mathrm{W}_{\mathrm{r}}$ is the free energy for the formation of the precursor complex (assumed here to be $\mathrm{W}_{\mathrm{r}}=2 \mathrm{kcal} / \mathrm{mol}$, see Section S1.C.III, SI), while the reorganization energy $\lambda$ is the energy required to distort the nuclei of the product state from the initial reactant geometry to the minimum product geometry. The experimental and DFT-calculated barriers are plotted in Figure 3a, along with the fits obtained using equation (2). The fit enabled us to evaluate the reorganization energy associated with $\mathrm{HT}$ from $\mathrm{R}-\mathrm{H}$ to $\mathrm{CO}_{2}$ and the values of 66 and $70 \mathrm{kcal} / \mathrm{mol}$ for experimental and calculated barriers were obtained.

Before we proceed to further discuss the analysis of reaction kinetics involving $\mathrm{CO}_{2}$, we briefly discuss the reactivity of organic hydrides toward protons. While the hydrogen-evolution reaction (HER) is often the most challenging competing process to avoid in electrocatalytic $\mathrm{CO}_{2}$ reduction, we found that our organic hydrides reduce protons to $\mathrm{H}_{2}$ in negligible yields ( $<2 \%$, Section S1C.IV). These experimental results are consistent with our DFT calculated barriers for water reduction by $\mathrm{HT}$ form $\mathrm{C} 1 \mathrm{H}-\mathrm{C} 8 \mathrm{H}$, which were computed to be in the $26-32 \mathrm{kcal} / \mathrm{mol}$ range (Figures 3a and 3c and SI Section S1C.IV). 
Returning to $\mathrm{CO}_{2}$ reduction kinetics, we further investigate different contributions to the reorganization energy $\lambda$. Specifically, $\lambda$ can be expressed in terms of symmetric self-exchange reorganization energies as:

$$
\lambda=\frac{\lambda_{R H}+\lambda_{\mathrm{CO} 2}}{2}
$$

The reorganization energies $\lambda_{\mathrm{R}-\mathrm{H}}$ and $\lambda_{\mathrm{CO} 2}$ are associated with the following self-exchange reactions:

$$
\begin{array}{cc}
\mathrm{RH}+\mathrm{R}^{+} \rightarrow \mathrm{R}^{+}+\mathrm{RH} & \lambda_{\mathrm{RH}} \\
\mathrm{HCOO}^{-}+\mathrm{CO}_{2} \rightarrow \mathrm{CO}_{2}+\mathrm{HCOO}^{-} & \lambda_{\mathrm{CO} 2}
\end{array}
$$

To estimate the $\lambda_{\mathrm{R}-\mathrm{H}}$ for our organo-hydrides, the self-exchange reorganization energy for $\mathrm{C} 4 \mathrm{H}$ was obtained experimentally to be $\lambda_{\mathrm{R}-\mathrm{H}}=91.2 \mathrm{kcal} / \mathrm{mol}$ (SI Section S1 C III(a)). This value is in excellent agreement with previously reported self-exchange energies of organic hydrides. ${ }^{36}$ Finally, $\lambda$ and $\lambda_{\mathrm{R}-\mathrm{H}}$ values were used to derive $\lambda_{\mathrm{co}}$ and the value of $41 \mathrm{kcal} / \mathrm{mol}$ was obtained, which is in good agreement with the DFT calculated value $\left(\lambda_{\mathrm{CO} 2}=56.4\right.$ $\mathrm{kcal} / \mathrm{mol}$, see Section S2.C, SI).

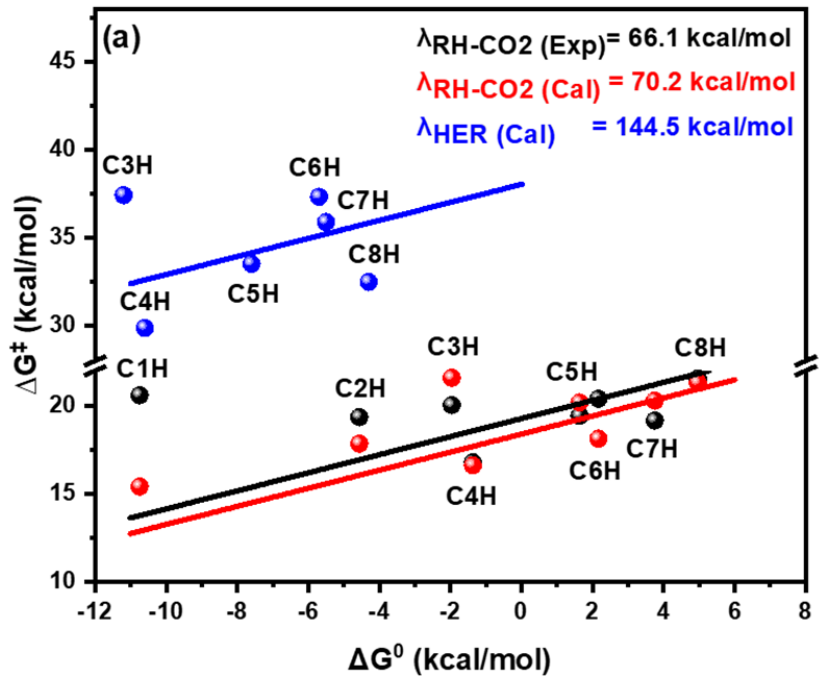

(b)

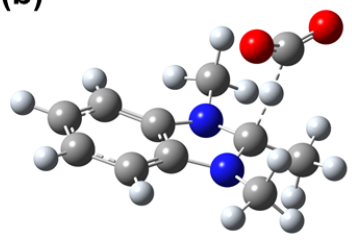

(c)

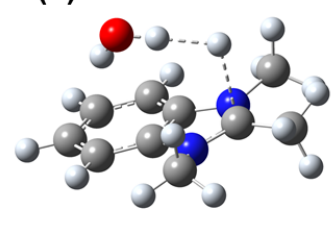

Figure 3. (a) The correlation between free energy barriers $\left(\Delta G^{\ddagger}\right)$ and reaction free energies $\left(\Delta G^{0}\right)$ for HT between $\mathrm{C} 1 \mathrm{H}-\mathrm{C} 8 \mathrm{H}$ and $\mathrm{CO}_{2}$ : experiment (black), calculation (red). Blue data show calculated values for HT to water (HER). Solid lines represent the fit to the Marcus model. (b) and (c) Calculated TS structures for $\mathrm{HT}$ from $\mathrm{C} 4 \mathrm{H}$ to (b) $\mathrm{CO}_{2}$ and (c) $\mathrm{H}_{2} \mathrm{O}$.

What information can be derived from these reorganization energies? To address this question, we evaluate the rate of HT for a hypothetical electrocatalyst operating at room temperature and at the thermodynamic driving force of $-0.1 \mathrm{eV}$ (to ensure a small overpotential). If the catalyst was made from our organic hydrides, the HT rate would be $1.7 \cdot 10^{-6} \mathrm{M}^{-1} \mathrm{~s}^{-1}$ (Table 1 ), which is prohibitively slow. The only way to reduce the barrier would involve identifying hydride donors with lower self-exchange reorganization energies. Indeed, metal-based hydride donors tend to have lower self-exchange reorganization energies. For example, a Ru-based hydride $[\mathrm{Ru}(\operatorname{trpy})(\mathrm{bpy}) \mathrm{H}]^{+}$was reported to have $\lambda_{\mathrm{R}-\mathrm{H}}=60.0 \mathrm{kcal} / \mathrm{mol},{ }^{37}$ which lowers our rate constant estimate to $1.1 \cdot 10^{-3} \mathrm{M}^{-1} \mathrm{~S}^{-1}$ (Table 1 ), a value that is still quite low. Interestingly, even if an ideal hydride donor was identified, with $\lambda_{\mathrm{R}-\mathrm{H}}=0 \mathrm{kcal} / \mathrm{mol}$, the rate constant would be relatively small $\left(4.5 \cdot 10^{2} \mathrm{M}^{-1} \mathrm{~S}^{-1}\right.$, Table 1$)$. This rate constant is barely sufficient for processes involving the use of solar energy, where catalytic rates in excess of 100 turnovers are needed to efficiently keep up with the photon flux at solar irradiance levels. ${ }^{38,39}$ Also, tate constants listed in Table 1 provide a plausible explanation for the fact that electrocatalytic $\mathrm{CO}_{2}$ reduction to the formate ion is rarely observed experimentally.

\begin{tabular}{|c|c|c|c|}
\hline $\begin{array}{l}\text { Hydride } \\
\text { Donor }\end{array}$ & $\underset{(\mathrm{kcal} / \mathrm{mol})}{\lambda_{(\mathrm{R}-\mathrm{H})}}$ & $\underset{(\mathrm{kcal} / \mathrm{mol})}{\lambda(\mathrm{H}-\mathrm{CO})}$ & $\begin{array}{c}\mathbf{k} \\
\mathbf{M}^{-1} \mathbf{S}^{-1}\end{array}$ \\
\hline NADH analog & 91.2 & 66.1 & $1.7 \cdot 10^{-6}$ \\
\hline$[\mathrm{Ru}(\operatorname{trpy})(\mathrm{bpy}) \mathrm{H}]^{+}$ & 60.0 & 50.5 & $1.1 \cdot 10^{-3}$ \\
\hline Ideal & 0 & 20.5 & $4.5 \cdot 10^{2}$ \\
\hline
\end{tabular}

Table 1: Summary of calculated $\lambda$ and hydride transfer rate constants at $25^{\circ} \mathrm{C}$ with $-0.1 \mathrm{eV}$ thermodynamic driving force.

What can be done to circumvent the observed kinetic barriers for direct $\mathrm{HT}$ to $\mathrm{CO}_{2}$ ? An interesting approach has been recently proposed by Yang, namely the orthogonal HT mechanism that involves a separate transfer of electrons and a proton to $\mathrm{CO}_{2} .^{40}$ In this bioinspired approach, the hydride-donating catalyst is replaced by a two-component catalytic system consisting of separate electron and proton donating groups. Using thermodynamic arguments, the authors show that the orthogonal HT can be efficiently utilized to break the scaling relationships associated with conventional HT. Here, we argue that the orthogonal HT could also provide an excellent solution to the kinetic challenges associated with conventional HT, since the kinetic barriers associated with electron and proton transfers are often much lower than those for HTs.

\section{AUTHOR INFORMATION}

Corresponding Author

glusac@uic.edu

ORCID

Ravindra B. Weerasooriya: 0000-0001-5311-4499

Jonathan L Gesiorski; 0000-0001-5770-0153 
Stefan Ilic: 0000-0002-6305-4001

Abdulaziz Alherz: 0000-0001-7529-3483

Charles B. Musgrave: 0000-0002-5732-3180

Ksenija D. Glusac: 0000-0002-2734-057X

\section{Acknowledgment}

This work was supported by the National Science Foundation (1954298 and 1565971).

\section{REFERENCES}

(1) Mellmann, D.; Sponholz, P.; Junge, H.; Beller, M. Formic Acid as a Hydrogen Storage MaterialDevelopment of Homogeneous Catalysts for Selective Hydrogen Release. Chem. Soc. Rev. 2016, 45 (14), 3954-3988.

(2) Bi, J.; Hou, P.; Kang, P. Single Iridium Pincer Complex for Roundtrip Electrochemical Conversion between Carbon Dioxide and Formate. ChemCatChem 2019, 11 (8), 2069-2072.

(3) Zhanaidarova, A.; Jones, S. C.; Despagnet-Ayoub, E.; Pimentel, B. R.; Kubiak, C. P. Re (TBu-Bpy)(CO) ${ }_{3} \mathrm{Cl}$ Supported on Multi-Walled Carbon Nanotubes Selectively Reduces $\mathrm{CO}_{2}$ in Water. J. Am. Chem. Soc. 2019, 141 (43), 17270-17277.

(4) Chen, Z.; Chen, C.; Weinberg, D. R.; Kang, P.; Concepcion, J. J.; Harrison, D. P.; Brookhart, M. S.; Meyer, T. J. Electrocatalytic Reduction of $\mathrm{CO}_{2}$ to $\mathrm{CO}$ by Polypyridyl Ruthenium Complexes. Chem. Commun. 2011, 47 (47), 12607-12609.

(5) Chen, Z.; Kang, P.; Zhang, M.-T.; Meyer, T. J. Making Syngas Electrocatalytically Using a Polypyridyl Ruthenium Catalyst. Chem. Commun. 2014, 50 (3), 335-337.

(6) Windle, C. D.; Pastor, E.; Reynal, A.; Whitwood, A. C.; Vaynzof, Y.; Durrant, J. R.; Perutz, R. N.; Reisner, E. Improving the Photocatalytic Reduction of $\mathrm{CO}_{2}$ to $\mathrm{CO}$ through Immobilisation of a Molecular Re Catalyst on $\mathrm{TiO}_{2}$. Chem. Eur. J. 2015, 21 (9), 3746-3754.

(7) Woolerton, T. W.; Sheard, S.; Reisner, E.; Pierce, E.; Ragsdale, S. W.; Armstrong, F. A. Efficient and Clean Photoreduction of $\mathrm{CO}_{2}$ to $\mathrm{CO}$ by Enzyme-Modified $\mathrm{TiO}_{2}$ Nanoparticles Using Visible Light. J. Am. Chem. Soc. 2010, 132 (7), 2132-2133.

(8) Kuehnel, M. F.; Orchard, K. L.; Dalle, K. E.; Reisner, E. Selective Photocatalytic $\mathrm{CO}_{2}$ Reduction in Water through Anchoring of a Molecular Ni Catalyst on CdS Nanocrystals. J. Am. Chem. Soc. 2017, 139 (21), 72177223.

(9) Kang, P.; Cheng, C.; Chen, Z.; Schauer, C. K.; Meyer, T. J.; Brookhart, M. Selective Electrocatalytic Reduction of $\mathrm{CO}_{2}$ to Formate by Water-Stable Iridium Dihydride
(10)

Pincer Complexes. J. Am. Chem. Soc. 2012, 134 (12), 5500-5503.

Waldie, K. M.; Brunner, F. M.; Kubiak, C. P. Transition Metal Hydride Catalysts for Sustainable Interconversion of $\mathrm{CO}_{2}$ and Formate: Thermodynamic and Mechanistic Considerations. ACS Sustain. Chem. Eng. 2018, 6 (5), 6841-6848.

Ceballos, B. M.; Yang, J. Y. Highly Selective Electrocatalytic $\mathrm{CO}_{2}$ Reduction by [Pt (Dmpe) 2] 2+ through Kinetic and Thermodynamic Control. Organometallics 2020, 39 (9), 1491-1496.

(12) Margarit, C. G.; Asimow, N. G.; Costentin, C.; Nocera, D. G. Tertiary Amine-Assisted Electroreduction of Carbon Dioxide to Formate Catalyzed by Iron Tetraphenylporphyrin. ACS Energy Lett. 2019, 5 (1), 72-78.

(13) Roy, S.; Sharma, B.; Pécaut, J.; Simon, P.; Fontecave, M.; Tran, P. D.; Derat, E.; Artero, V. Molecular Cobalt Complexes with Pendant Amines for Selective Electrocatalytic Reduction of Carbon Dioxide to Formic Acid. J. Am. Chem. Soc. 2017, 139 (10), 36853696.

(14) Ceballos, B. M.; Yang, J. Y. Directing the Reactivity of Metal Hydrides for Selective $\mathrm{CO}_{2}$ Reduction. Proc. Natl. Acad. Sci. 2018, 115 (50), 12686-12691.

(15) Loewen, N. D.; Neelakantan, T. V; Berben, L. A. Renewable Formate from C-H Bond Formation with $\mathrm{CO}_{2}$ : Using Iron Carbonyl Clusters as Electrocatalysts. Acc. Chem. Res. 2017, 50 (9), 2362-2370.

(16) Taheri, A.; Berben, L. A. Tailoring Electrocatalysts for Selective $\mathrm{CO}_{2}$ or $\mathrm{H}+$ Reduction: Iron Carbonyl Clusters as a Case Study. Inorg. Chem. 2016, 55 (2), 378-385.

(17) Taheri, A.; Thompson, E. J.; Fettinger, J. C.; Berben, L. A. An Iron Electrocatalyst for Selective Reduction of $\mathrm{CO}_{2}$ to Formate in Water: Including Thermochemical Insights. ACS Catal. 2015, 5 (12), 7140-7151.

(18) Ramakrishnan, S.; Moretti, R. A.; Chidsey, C. E. D. Mapping Free Energy Regimes in Electrocatalytic Reductions to Screen Transition Metal-Based Catalysts. Chem. Sci. 2019, 10 (32), 7649-7658.

(19) Waldie, K. M.; Ostericher, A. L.; Reineke, M. H.; Sasayama, A. F.; Kubiak, C. P. Hydricity of TransitionMetal Hydrides: Thermodynamic Considerations for $\mathrm{CO}_{2}$ Reduction. ACS Catal. 2018, 8 (2), 1313-1324.

(20) Barlow, J. M.; Yang, J. Y. Thermodynamic Considerations for Optimizing Selective $\mathrm{CO}_{2}$ Reduction by Molecular Catalysts. ACS Cent. Sci. 2019, 5 (4), 580-588.

(21) Johnson, S. I.; Nielsen, R. J.; Goddard III, W. A. Selectivity for $\mathrm{HCO}_{2}-$ over $\mathrm{H}_{2}$ in the Electrochemical Catalytic Reduction of $\mathrm{CO}_{2}$ by (POCOP) $\mathrm{IrH}_{2}$. ACS Catal. 2016, 6 (10), 6362-6371. 
(22) Schneider, G.; Lindqvist, Y.; Branden, C.-I. RUBISCO: Structure and Mechanism. Annu. Rev. Biophys. Biomol. Struct. 1992, 21 (1), 119-143.

(23) Ilic, S.; Alherz, A.; Musgrave, C. B.; Glusac, K. D. Thermodynamic and Kinetic Hydricities of MetalFree Hydrides. Chem. Soc. Rev. 2018, 47 (8), 28092836.

(24) Ilic, S.; Pandey Kadel, U.; Basdogan, Y.; Keith, J. A.; Glusac, K. D. Thermodynamic Hydricities of Biomimetic Organic Hydride Donors. J. Am. Chem. Soc. 2018, 140 (13), 4569-4579.

(25) Hargenrader, G. N.; Weerasooriya, R. B.; Ilic, S.; Niklas, J.; Poluektov, O. G.; Glusac, K. D. Photoregeneration of Biomimetic Nicotinamide Adenine Dinucleotide Analogues via a Dye-Sensitized Approach. ACS Appl. Energy Mater. 2019, 2 (1), 80-91.

(26) Lim, C.-H.; Ilic, S.; Alherz, A.; Worrell, B. T.; Bacon, S. S.; Hynes, J. T.; Glusac, K. D.; Musgrave, C. B. Benzimidazoles as Metal-Free and Recyclable Hydrides for $\mathrm{CO}_{2}$ Reduction to Formate. J. Am. Chem. Soc. 2018, 141 (1), 272-280.

(27) Ilic, S.; Alherz, A.; Musgrave, C. B.; Glusac, K. D. Importance of Proton-Coupled Electron Transfer in Cathodic Regeneration of Organic Hydrides. Chem. Commun. 2019, 55 (39), 5583-5586.

(28) Lim, C.-H.; Holder, A. M.; Hynes, J. T.; Musgrave, C. B. Reduction of $\mathrm{CO}_{2}$ to Methanol Catalyzed by a Biomimetic Organo-Hydride Produced from Pyridine. J. Am. Chem. Soc. 2014, 136 (45), 1608116095.

(29) Tsay, C.; Yang, J. Y. Electrocatalytic Hydrogen Evolution under Acidic Aqueous Conditions and Mechanistic Studies of a Highly Stable Molecular Catalyst. J. Am. Chem. Soc. 2016, 138 (43), 1417414177.

(30) Wiedner, E. S.; Linehan, J. C. Making a Splash in Homogeneous $\mathrm{CO}_{2}$ Hydrogenation: Elucidating the Impact of Solvent on Catalytic Mechanisms. Chem. Eur. J. 2018, 24 (64), 16964-16971.

(31) Creutz, C.; Chou, M. H. Rapid Transfer of Hydride Ion from a Ruthenium Complex to $\mathrm{C}_{1}$ Species in Water. J. Am. Chem. Soc. 2007, 129 (33), 10108-10109.
M. Photochemical Reduction of Carbon Dioxide to Methanol and Formate in a Homogeneous System with Pyridinium Catalysts. J. Am. Chem. Soc. 2013, 135 (44), 16252-16255.

(33) Qiao, J.; Liu, Y.; Hong, F.; Zhang, J. A Review of Catalysts for the Electroreduction of Carbon Dioxide to Produce Low-Carbon Fuels. Chem. Soc. Rev. 2014, 43 (2), 631-675.

(34) Mayer, J. M. Simple Marcus-Theory-Type Model for Hydrogen-Atom Transfer/Proton-Coupled Electron Transfer. J. Phys. Chem. Lett. 2011, 2 (12), 14811489.

(35) Brinkley, D. W.; Roth, J. P. Determination of a Large Reorganization Energy Barrier for Hydride Abstraction by Glucose Oxidase. J. Am. Chem. Soc. 2005, 127 (45), 15720-15721.

(36) Lee, I.-S. H.; Jeoung, E. H.; Kreevoy, M. M. Marcus Theory of a Parallel Effect on $\alpha$ for Hydride Transfer Reaction between NAD+ Analogues. J. Am. Chem. Soc. 1997, 119 (11), 2722-2728.

(37) Matsubara, Y.; Fujita, E.; Doherty, M. D.; Muckerman, J. T.; Creutz, C. Thermodynamic and Kinetic Hydricity of Ruthenium (II) Hydride Complexes. J. Am. Chem. Soc. 2012, 134 (38), 15743-15757.

(38) Lewis, N. S.; Crabtree, G.; Nozik, A. J.; Wasielewski, M. R.; Alivisatos, P.; Kung, H.; Tsao, J.; Chandler, E.; Walukiewicz, W.; Spitler, M. Basic Research Needs for Solar Energy Utilization. Report of the Basic Energy Sciences Workshop on Solar Energy Utilization, April 18-21, 2005; DOESC (USDOE Office of Science (SC)), 2005.

(39) Arakawa, H.; Aresta, M.; Armor, J. N.; Barteau, M. A.; Beckman, E. J.; Bell, A. T.; Bercaw, J. E.; Creutz, C.; Dinjus, E.; Dixon, D. A. Catalysis Research of Relevance to Carbon Management: Progress, Challenges, and Opportunities. Chem. Rev. 2001, 101 (4), 953-996.

(40) Yang, J. Y.; Kerr, T. A.; Wang, X. S.; Barlow, J. M. Reducing $\mathrm{CO}_{2}$ to $\mathrm{HCO}_{2}^{-}$at Mild Potentials: Lessons from Formate Dehydrogenase. J. Am. Chem. Soc. 2020. 
Insert Table of Contents artwork here

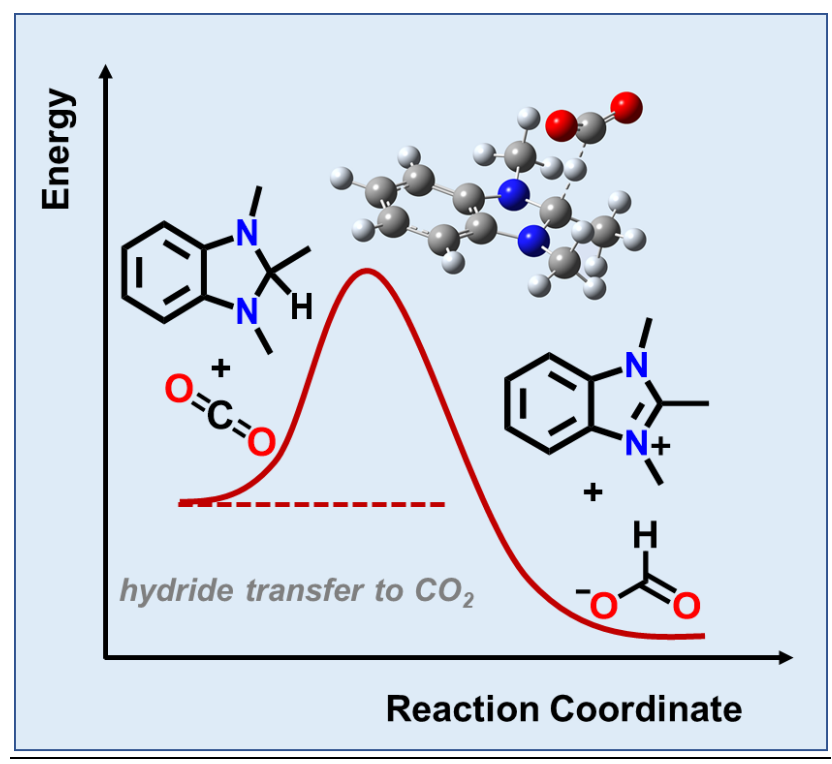

